\section{Pollination Compatibility and Xenia in Camellia oleifera}

Guanxing Hu

Key Laboratory of Cultivation and Protection for Non-Wood Forest Trees of Ministry of Education and the Key Laboratory of Non-Wood Forest Products of Forestry Ministry, Central South University of Forestry and Technology, Changsha, Hunan, 410004, China

\section{Chao Gao}

Key Laboratory of Cultivation and Protection for Non-Wood Forest Trees of Ministry of Education and the Key Laboratory of Non-Wood Forest Products of Forestry Ministry, Central South University of Forestry and Technology, Changsha, Hunan, 410004, China; and the Institute for Forest Resources \& Environment of Guizhou, Guizhou University, Guiyang, Guizhou, 550025, China

\section{Xiaoming Fan, Wenfang Gong, and Deyi Yuan}

Key Laboratory of Cultivation and Protection for Non-Wood Forest Trees of Ministry of Education and the Key Laboratory of Non-Wood Forest Products of Forestry Ministry, Central South University of Forestry and Technology, Changsha, Hunan, 410004, China

Additional index words. cross-pollination, pollen, self-pollination, tea oil

\begin{abstract}
Camellia oleifera, a major woody oil plant, has a low oil yield because of self-incompatibility. For commercial oil production, compatible pollen and optimal cross-pollination combinations are required. To evaluate the effects of pollination compatibility and pollen source on oil yield and quality, four $C$. oleifera cultivarsHuashuo (HS), Huajin (HJ), Huaxin (HX), and Xianglin XLC15 (XL)—were subjected to self-, cross-, and natural pollination. Pollen compatibility, oil yield, and quality indices were analyzed. There were no significant differences in pollen germination and tube growth between self- and cross-pollination. Following self-pollination, fertilization was unsuccessful, resulting in severe ovule dysplasia; cross-pollination decreased the ovule abortion rate. Pollen source significantly affected the fruit set, fruit traits, seed traits, and fatty acid content, implying xenia in $\boldsymbol{C}$. oleifera. In cross-pollinated plants, HX pollen produced more seeds, and $\mathrm{HJ}$ pollen increased linoleic acid content relative to naturally pollinated plants. For the XL and HS combinations, linolenic acid contents were significantly higher than other pollination combinations. However, oleic acid content was not significantly affected by pollen source, in any of the cultivars. Cultivar $\mathrm{HX}$ was, therefore, the most effective pollen donor, and HS $\times$ HX was the optimal crosspollination combination for improving oil yield and sustainability.
\end{abstract}

Received for publication 24 Feb. 2020. Accepted for publication 30 Mar. 2020.

Published online 14 May 2020

This work was supported by The National Key R\&D Program of China (2018YFD1000603-1), Research and Demonstration on Key Technologies of New Generation Camellia oleifera Germplasm Creation (2018NK1030-02), Scientific Innovation Fund for Post-graduates of Central South University of Forestry and Technology (20183032) and Science and Technology Planning Projects of Guizhou (Qian Ke He [2019]2310).

We thank Erica Romain, Derek J. Forrester, and Mian Faisal Nazir for the modification of article language.

W.G. and D.Y. are the corresponding authors. E-mail: gwf018@126.com or yuan-deyi@163. com.

This is an open access article distributed under the CC BY-NC-ND license (https://creativecommons. org/licenses/by-nc-nd/4.0/).
Paeonia suffruticosa, pollen source was found to affect seed yield and even the fatty acid composition of seed oil (Xie et al., 2017).

Self-incompatibility usually refers to the phenomenon in which a fertile hermaphrodite seed plant cannot produce zygotes after self-pollination. Based on the type of genetic control of pollen recognition, selfincompatibility can be divided into gametophytic self-incompatibility (GSI) and sporophytic self-incompatibility (SSI) (Takayama and Isogai, 2005; Zhou and Zheng, 2015). For instance, citrus (Jahromi et al., 2019), plum (Jia et al., 2008), and pear (Wang et al., 2017) have GSI, whereas Brassicaceae (Higashiyama, 2010) and Asteraceae species (Faehnrich et al., 2015) have SSI. Fertilization can be unsuccessful even if the pollen tube manages to enter the style or ovule; this is called late-acting self-incompatibility or ovarian self-incompatibility (Asatryan and Tel-Zur, 2013; Gao et al., 2015a; Seavey and Bawa, 1986). For instance, Chen et al. (2012) observed that in Camellia sinensis self-pollination, pollen tubes successfully elongated through the style, but they had difficulty in entering the ovule, causing fertilization to fail.

Camellia oleifera, one of the world's four major woody oil plants, produces edible tea oil with $\approx 75 \%$ to $83 \%$ oleic acid and $7 \%$ to $13 \%$ linoleic acid; these acids are able to soften blood vessels, lower blood lipids, and reduce blood pressure (Cheng et al., 2014). The area under $C$. oleifera cultivation in China exceeds 4.6 million ha; however, its cultivation is limited by several problems, including low fruit set and poor fruit quality (Wen et al., 2018). The low yield of $C$. oleifera has long hampered the development of this industry in China (Gao et al., 2015a), and therefore it needs to be addressed urgently. Several studies have been conducted on pollination and embryo development (Liao et al., 2014a), self-compatibility (Gao et al., 2015a), and the pollination effectiveness of various insects for this species (Wei et al., 2019). However, the effects of using different pollen donors on $C$. oleifera oil yield and quality have not been explored. Selection of the appropriate pollen may improve the fruit set and fruit quality of $C$. oleifera.

The four C. oleifera cultivars-Huashuo (HS), Huajin (HJ), Huaxin (HX), and Xianglin XLC15 (XL) - are widely grown in China, and they show the greatest potential for oil production. To screen them for compatible pollen and optimal pollination combinations, their pollination compatibility, pollen germination, and pollen tube growth were observed. In addition, the effects of using different pollen sources on $C$. oleifera ovule abortion, fruit set, fruit traits, seed traits, and fatty acid content were compared. Finally, principal component analysis (PCA) was used to evaluate the influence of different pollen on $C$. oleifera oil yield and quality, and to screen compatible pollen and determine the optimal pollination combinations. 
Scientific selection of pollination cultivars (pollen donors) could improve $C$. oleifera oil yield and quality. This study provides a basis for the scientific selection of pollination cultivars of these four $C$. oleifera cultivars.

\section{Materials and Methods}

Study site and plant material. The study used 6-year-old, high-crown grafted $C$. oleifera cultivars (HS, HJ, HX, and XL) that had reached their peak production stage and showed similar growth potential and consistent management. The trees were planted in the experimental field of the Central South Forestry University of Science and Technology, Changsha, China (lat. $28^{\circ} 05^{\prime} \mathrm{N}$, long. $\left.113^{\circ} 21^{\prime} \mathrm{E}\right)$. This area belongs to the subtropical, humid, monsoon climate zone, with rainy springs and sunny autumns. The annual average precipitation, temperature, and accumulated temperature of the experimental site are $1380 \mathrm{~mm}, 19.3{ }^{\circ} \mathrm{C}$, and $5463{ }^{\circ} \mathrm{C}$, respectively.

Experimental design. Cross-, self-, and natural pollinations were carried out using the four C. oleifera cultivars. Twenty trees of each cultivar were randomly selected as female parents. At the full flowering stage, $\approx 80$ buds from the middle and upper crown of each tree were selected for the pollination experiment, using specific pollination combinations (Supplemental Table 1). Anthers were manually removed, pollinated, bagged, and labeled in cross- and self-pollinating plants. Untreated flowers that opened on the same day were selected for natural pollination. Each pollination combination included at least 100 buds and was repeated three times. After $7 \mathrm{~d}$, the pollination isolation bags were removed. The number of fruits on each branch of each experimental tree remained about the same during the experiment. The pollen tube growth and ovule penetration of cross- and self-pollinating plants were observed. Ninety days after pollination, the fruit set of each pollination combination was investigated. Mature fruits were randomly selected to compare fruit traits, seed traits, and fatty acid contents (Fig. 1).

Pollen collection and germination test. The buds of four $C$. oleifera cultivars were harvested at the bell stage. The anthers were collected and dried at $25^{\circ} \mathrm{C}$ until the pollen was released (usually $24 \mathrm{~h}$ ). Then the pollen was placed on culture medium consisting of $10 \mathrm{~g} \cdot \mathrm{L}^{-1}$ agar, $0.1 \mathrm{~g} \cdot \mathrm{L}^{-1}$ boric acid, and 100 $\mathrm{g} \cdot \mathrm{L}^{-1}$ sucrose at $25^{\circ} \mathrm{C}$. After $4 \mathrm{~h}$, pollen germination was observed under an Olympus BX-51 microscope (Olympus, Tokyo, Japan). If the length of the pollen tube exceeded the diameter of the pollen grain, the pollen was defined as germinating.

Observation of pollen tube growth, ovule penetration, and fruit development. The pistils were collected $2,4,6,12,24,28,32$, $36,40,44,48,54,60,66$, and $72 \mathrm{~h}$ after selfand cross-pollination. The collected pistils were immediately fixed in Carnoy's fixative [95\% ethanol:glacial acetic acid (v/v, 3:1)] for $12 \mathrm{~h}$. After undergoing vacuum treatment, the material was transferred to a solution of $70 \%$ ethanol and stored at $4{ }^{\circ} \mathrm{C}$.

Fluorescence microscopy was used to observe pollen tube growth. Briefly, this involved scraping off the ovary wall of the pistil, and then cutting each style with the lower ovary along the central axis (placenta). This was soaked in $\mathrm{NaClO}$ solution (effective chlorine content, $9000 \mathrm{mg} \cdot \mathrm{L}^{-1}$ ) for $2 \mathrm{~h}$. After rinsing with distilled water, styles were transferred to a 8 -mol. $\mathrm{L}^{-1} \mathrm{NaOH}$ solution and soaked for $2 \mathrm{~h}$. The styles were rinsed with distilled water three times, and then stained with $0.5 \%$ water-soluble aniline blue dyeing solution for $6 \mathrm{~h}$. Finally, the style was spread onto a thin glass slide (using a few drops of aniline blue staining solution), and observed and photographed under a glass slide cover, using an Olympus BX-51 fluorescence microscope.

To observe ovule penetration, conventional paraffin sections with a thickness of $13 \mu \mathrm{m}$ were used. After dewaxing and rehydration, ovules were stained with $0.3 \%$ aniline blue solution for $2 \mathrm{~h}$, and then observed and photographed under an Olympus BX-51 fluorescence microscope.

At $180 \mathrm{~d}$ after pollination, the self- and cross-pollinated fruits were harvested, and ovule development was observed and photographed under an Olympus SZX16 stereomicroscope (Olympus, Tokyo, Japan).

Fruit yield, fruit quality, and fatty acid analysis. Ninety days after pollination, the fruit set of each pollination combination was recorded. Mature fruits were randomly selected from each combination to assess fruit yield and quality. The single fruit weight, hundred-grain weight, fresh seed weight, dry seed weight, and kernel weight were measured using an electronic balance; and fruit transverse diameter, vertical diameter, and peel thickness were measured using an electronic digital caliper as described by You et al. (2019). Seed number (the number of seeds produced) was the average number of normally developing seeds in 10 fruits, and seed shell color was described according to Zhuang (2008). Oil extraction for the analysis of seed-kernel oil concentration was performed using Soxtec 2050 (Foss Analytical, Hillerød, Denmark) following the manufacturer's manual.

Yield indices were evaluated as follows: fresh seed rate $(\%)=($ fresh seed weight $/$ fresh fruit weight $) \times 100$; dry seed rate $(\%)=($ dry seed weight/fresh seed weight $) \times 100$; kernel rate $(\%)=($ kernel weight/dry seed weight $)$; and kernel oil rate $(\%)=($ oil weight $/$ kernel weight) $\times 100$.

Fatty acid composition was analyzed using a gas chromatograph (Shimadzu GC2014; Shimadzu, Kyoto, Japan); the relative content of each fatty acid was calculated according to the method of Zhang et al. (2019). The gas chromatograph parameters were as follows: FID detector temperature $250{ }^{\circ} \mathrm{C}$; sample inlet temperature $250{ }^{\circ} \mathrm{C}$; chromatographic column $60 \mathrm{~m} \times 0.25 \mathrm{~mm} \times$ $0.2 \mu \mathrm{m}$; carrier gas: nitrogen split ratio 1:50; sample injection volume $1 \mu \mathrm{L}$. The heating process was as follows: $50{ }^{\circ} \mathrm{C}$ for $2 \mathrm{~min}$, increased to $170{ }^{\circ} \mathrm{C}$ at $10{ }^{\circ} \mathrm{C} \cdot \mathrm{min}^{-1}$, and maintained for $10 \mathrm{~min}$; increased to $180{ }^{\circ} \mathrm{C}$ at $2{ }^{\circ} \mathrm{C} \cdot \mathrm{min}^{-1}$, and maintained for $10 \mathrm{~min}$; and finally, increased to $220^{\circ} \mathrm{C}$ at $4^{\circ} \mathrm{C} \cdot \mathrm{min}^{-1}$, and maintained for $22 \mathrm{~min}$.

Principal component analysis. PCA is defined as an orthogonal linear transformation system that transforms the data onto a new coordinate system, such that the largest amount of variance explained by some scalar projection of the data comes to lie on the first coordinate (called the first principal component, PC1), the second largest amount of the variance on the second coordinate (PC2), and so on (Upadyayula et al., 2006). PCA was performed using SPSS 21.0 (SPSS Inc., Chicago, IL); and the fruit trait, seed trait, and fatty acid content values were standardized using the procedure "Save standardized values as variables" in the Descriptive Statistics module. The correlation matrix, composition matrix, eigenvalues, and variances were generated using the "Factor Analysis" tool in the Data Reduction module, and the PCs were extracted when a factor's eigenvalue was more than one. The eigenvectors (coefficients) of each PC were calculated using the procedure "Compute Variable" in the Transform module, as follows: eigenvector $=$ composition matrix/sqrt(eigenvalue). The weights used to calculate coefficients of comprehensive PC score model were the ratios of each PC's eigenvalue, to the sum of the eigenvalues of the extracted PCs.

Statistical analysis. The experiments were performed in triplicate. SPSS version 21.0 was used for data processing. To identify statistically significant differences in the fruit set, fruit traits, seed traits, and fatty acid contents for each cultivar obtained using the different pollen donors, the data were analyzed using one-way analysis of variance (ANOVA), at a significance level of $P<$ 0.05 . This was followed by a least significant difference (LSD) multiple comparisons test, where LSD $=t_{0.05 / 2} ; D F w \sqrt{M S w\left(\frac{1}{n_{A}}+\frac{1}{n_{B}}\right)}$ and $M S w$ is the mean square within groups determined by ANOVA. Figures were drawn using Origin 9.1 (OriginLab, Northampton, MA).

\section{Results}

Pollen germination and pollen tube growth in self-pollination and crosspollination experiments. Camelia oleifera has a long flowering period, ranging from late October to early December. The flowering periods were mostly the same for the four cultivars (Supplemental Fig. 1). The pollen germination rates of $\mathrm{HS}, \mathrm{HJ}, \mathrm{HX}$, and $\mathrm{XL}$ were $82.95 \%, 72.23 \%, 87.47 \%$, and $81.60 \%$, respectively (Fig. 2, Supplemental Fig. 2), indicating that they have good pollen vitality. The pollen tubes in self-pollination (Fig. 3AD) and cross-pollination experiments (Fig. 3E-H) germinated easily at the stigma and grew inside the style $2 \mathrm{~h}$ after pollination. 


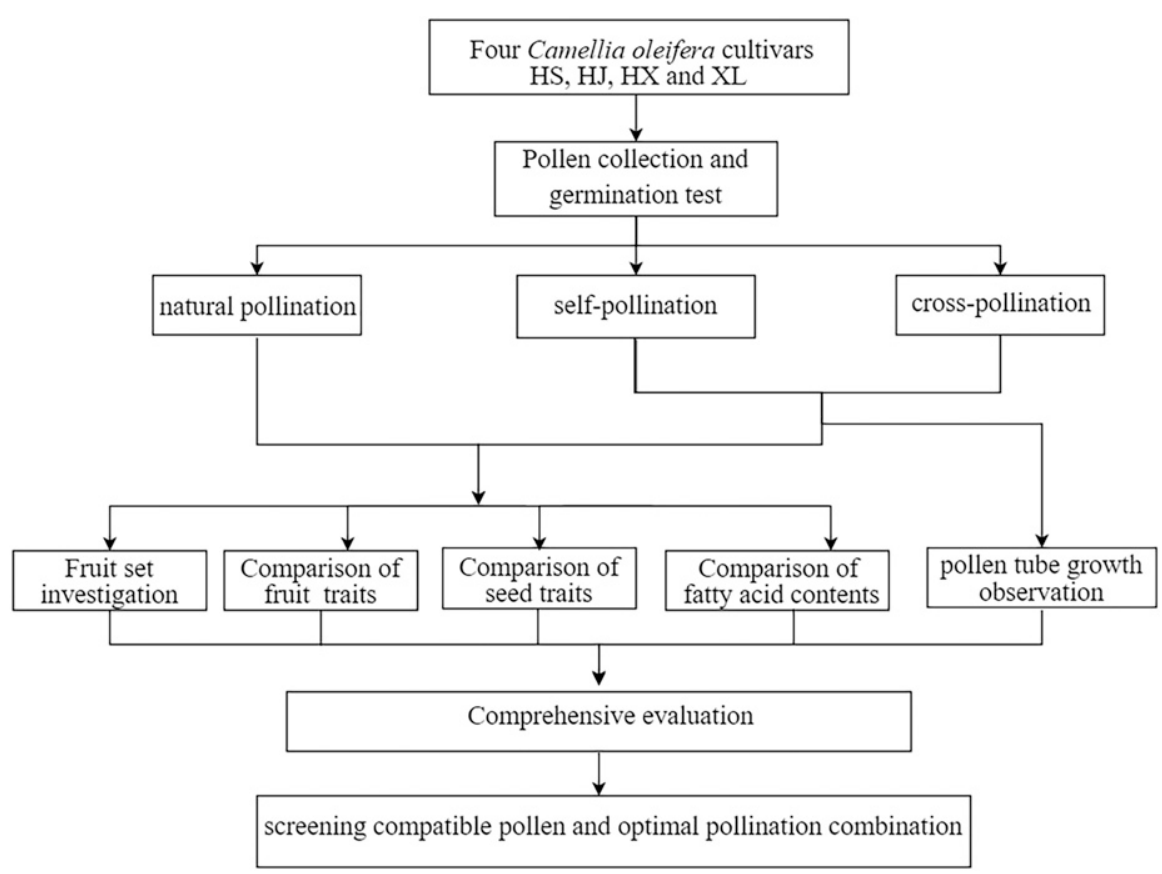

Fig. 1. Schematic representation of the experimental design. The main objective of the study was to screen compatible pollen and optimal pollination combinations of four C. oleifera cultivars (HS, HJ, HX, and $\mathrm{XL}$ ). Cross-pollination, self-pollination, and natural pollination were carried out in the four cultivars. Anthers were manually removed, pollinated, bagged, and labeled in cross- and self-pollinating plants. Untreated flowers that opened on the same day were selected for natural pollination. Pollen tube growth of cross- and self-pollinating plants were observed. To analyze pollen compatibility, pollen tube growth and ovule penetration were observed in the pistils collected 2, 4, 6, 12, 24, 28, 32, 36, 40, 44, 48, 54, 60, 66 , and $72 \mathrm{~h}$ after self- and cross-pollination. Ninety days after pollination, the fruit set of each pollination combination was investigated. Mature fruits were randomly selected to compare fruit traits, seed traits, and fatty acid contents. PCA was used to evaluate the influence of different pollen on C. oleifera oil yield and quality, and to screen compatible pollen and determine the optimal pollination combinations.

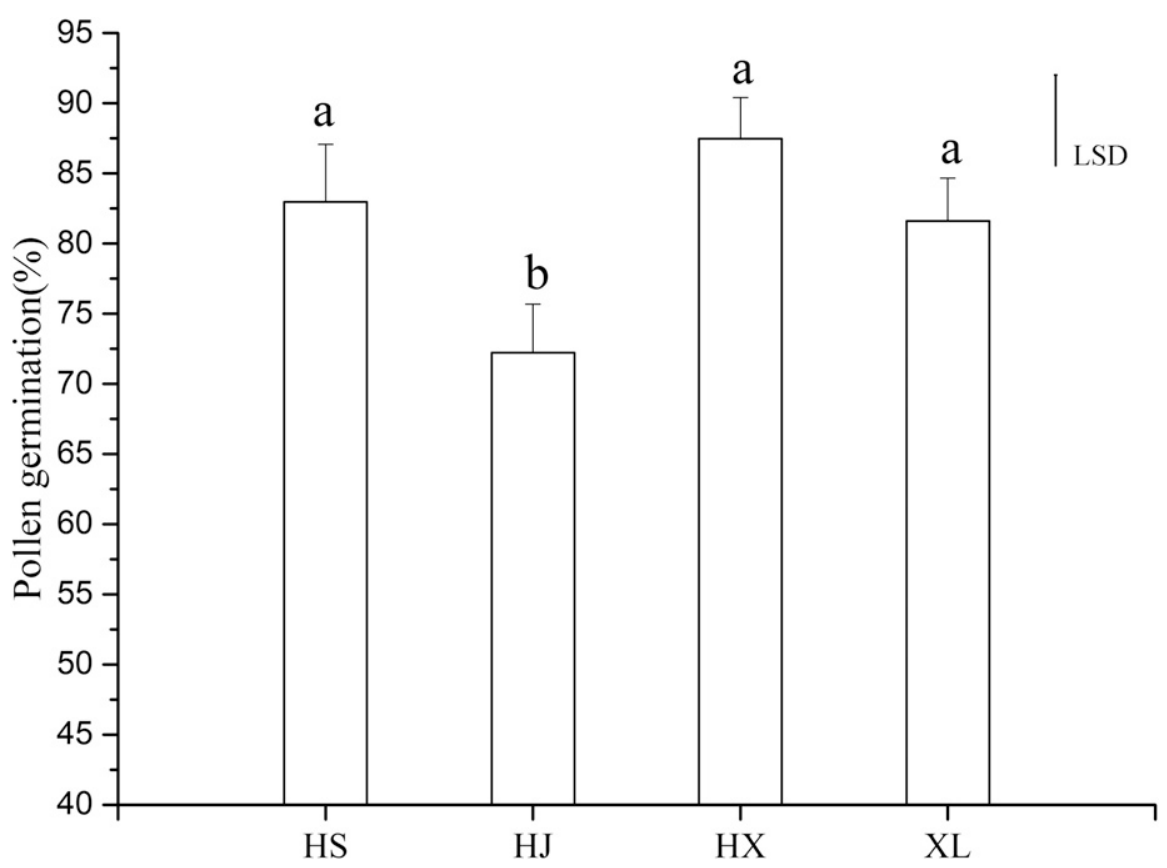

Fig. 2. Pollen germination of four $C$. oleifera cultivars on the culture medium. The data are the mean $\pm \mathrm{SD}$ of three biological replicates, and different lowercase letters indicate significant differences at $5 \%$ probability level in a least significant difference (LSD) test.

About $40 \mathrm{~h}$ after pollination, the pollen tubes reached the base of the style in both the selfpollination (Supplemental Fig. 3A-D) and cross-pollination experiments (Supplemental Fig. $3 \mathrm{E}-\mathrm{H}$ ). After $40-48 \mathrm{~h}$, the pollen tubes of the cross-pollinated plants continued to grow downward to the ovule (Fig. 4E-H). However, the growth of the pollen tubes of the self-pollinated plants slowed down, and the tubes eventually stagnated at the ovary (Fig. 4A-D).

Fruit set and ovule development in selfand cross-pollinated combinations. Using pollen from different cultivars had a significant influence on fruit set. The fruit set was significantly lower in self-pollinated plants than in naturally pollinated and crosspollinated plants (Fig. 5). In the self-pollination experiment, the cultivar $\mathrm{HJ}$ had the highest fruit set (14.04\%) among the four cultivars. In the cross-pollination treatment, the fruit set of HS ranged from $72.60 \%$ to $81.85 \%$. In addition, the cultivars $\mathrm{HJ}$ (pollinated by $\mathrm{XL}$ and HX) and XL (using HS pollen) had significantly higher fruit set values than the other cultivars. In the cross-pollination treatment, the highest fruit set values of $\mathrm{HS}, \mathrm{HJ}, \mathrm{HX}$, and XL were $50.67 \%, 39.82 \%, 41.72 \%$, and $37.36 \%$ higher, respectively, than those of naturally pollinated plants.

The fruits of the self- and cross-pollinated plants were dissected $180 \mathrm{~d}$ after pollination. In the fruits of the self-pollinated plants, only one to two ovules developed normally, and most of the ovules turned brown (Fig. 6AL). However, the ovules of the fruits of the cross-pollinated plants developed normally (Supplemental Fig. 4A-L). These results suggest that cross-pollination significantly decreased the ovule abortion rate in $C$. oleifera.

Effects of pollen source on seed shell color, single fruit weight, vertical and horizontal diameter, and peel thickness. Pollen source had a significant effect on seed shell color in the four cultivars (Supplemental Fig. 5). In all four cultivars, crosssectioning of fruits from plants pollinated by HX showed that seed shell color was distinctly black, while that of plants pollinated by HS was brown.

The single fruit weight of self-pollinated plants was significantly lower than that of cross-pollinated and naturally pollinated plants (Table 1). Compared with natural pollination, pollination with $\mathrm{HX}$ as pollen donor led to the single fruit weight of HS, HJ, and XL being higher by $141.43 \%$, $74.31 \%$, and $53.57 \%$, respectively. Pollination using $\mathrm{HJ}$ and XL pollen led to the single fruit weight of HX being higher by $27.02 \%$ and $32.12 \%$, respectively, than that of naturally pollinated plants. In contrast, the single fruit weights of the combinations $\mathrm{HJ} \times$ $\mathrm{HS}, \mathrm{HJ} \times \mathrm{XL}, \mathrm{HX} \times \mathrm{HS}$, and $\mathrm{XL} \times \mathrm{HS}$ did not differ notably from that of naturally pollinated plants. The effects of the different pollen sources on fruit diameter and peel thickness were almost the same as their effects on single fruit weight.

Effects of pollen source on seed number, hundred-grain weight, fresh seed rate, dry seed rate, kernel rate, and kernel oil rate. Among the self-pollinated plants, each cultivar had two to three seeds per fruit. In cross-pollinated plants, $\mathrm{HJ}, \mathrm{HX}$, and $\mathrm{XL}$ produced different numbers of seeds when 

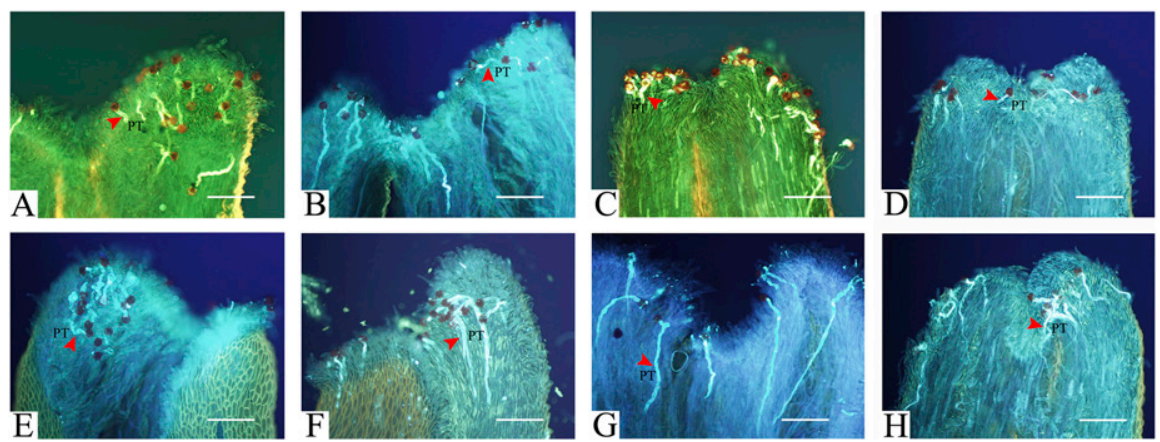

Fig. 3. Pollen germination in the style at $2 \mathrm{~h}$ after self- and cross-pollination. Pollen grains germinated from the stigma and pollen tubes (PT) grew into the interspaces between the papillar cells in self-pollinated $\mathrm{HS}(\mathbf{A}), \mathrm{XL}(\mathbf{B}), \mathrm{HJ}(\mathbf{C})$, and $\mathrm{HX}$ (D) plants and cross-pollinated $\mathrm{HS} \times \mathrm{XL}(\mathbf{E}), \mathrm{XL} \times \mathrm{HS}(\mathbf{F}), \mathrm{HJ} \times \mathrm{HX}$ (G), and $\mathrm{HX} \times \mathrm{HJ}(\mathbf{H})$ plants. Bars A-H: $1000 \mu \mathrm{m}$.
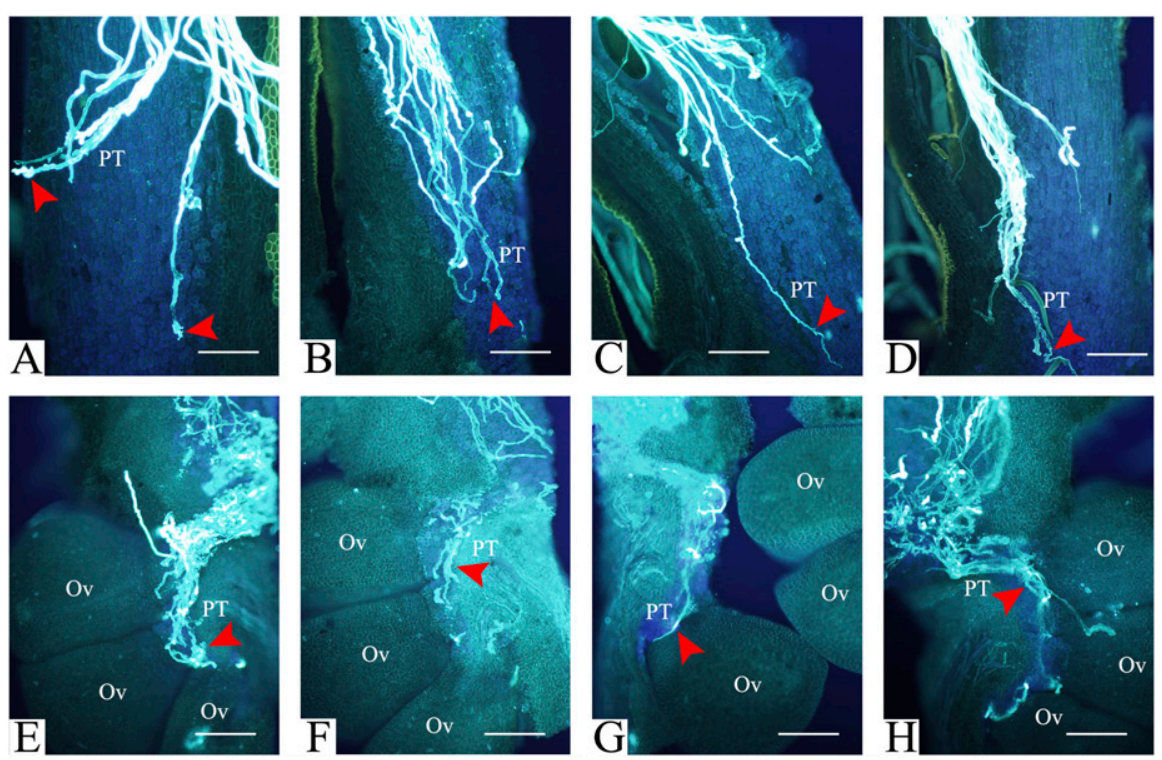

Fig. 4. The pollen tube growth in style after self- and cross-pollination. At $40 \mathrm{~h}$ after self -pollination of HS (A), XL (B), HJ (C), and HX (D), the pollen tubes (PT, indicated by arrows, fluorescence micrograph $\times 100)$ grew to the stylar base. At $48 \mathrm{~h}$ after cross-pollination of $\mathrm{HS} \times \mathrm{XL}(\mathbf{E}), \mathrm{XL} \times \mathrm{HS}(\mathbf{F})$, $\mathrm{HJ} \times \mathrm{HX}(\mathbf{G})$, and $\mathrm{HX} \times \mathrm{HJ}(\mathbf{H})$, the pollen tubes entered the ovary ovule $(\mathrm{OV})$.

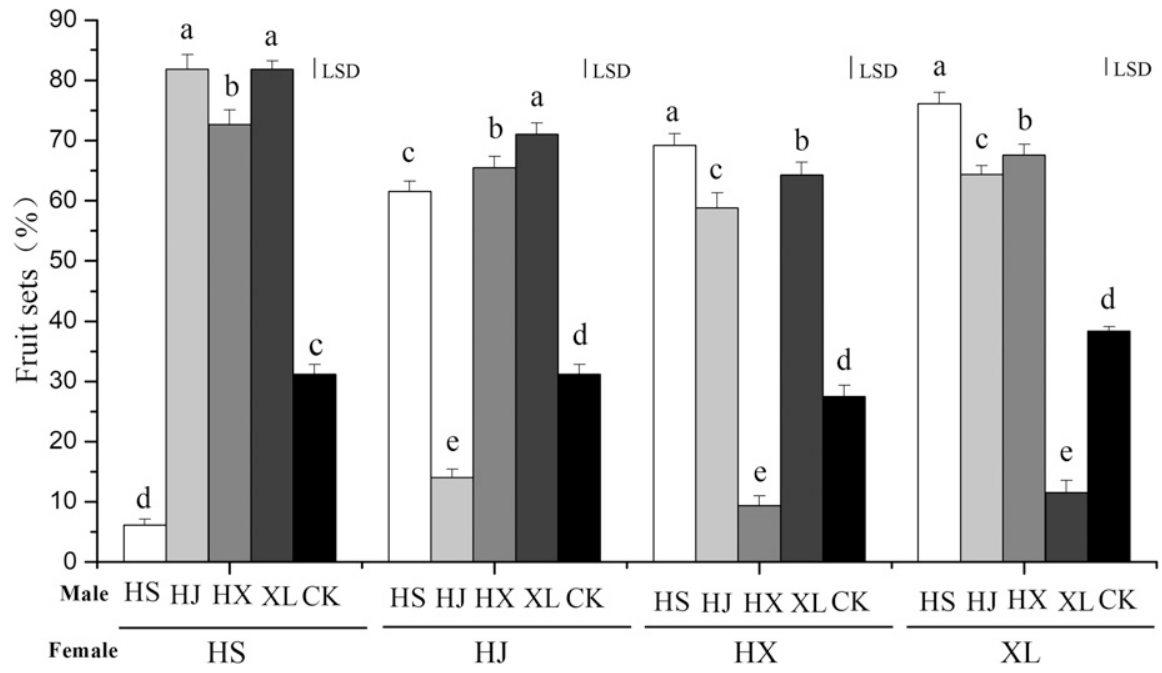

Fig. 5. The fruit set of different pollination combinations. The data are the mean \pm SD of three biological replicates, and different lowercase letters indicate significant differences at $5 \%$ probability level in a least significant difference (LSD) test. they were pollinated using different pollen donors, whereas HS was unaffected by the pollen source (Table 2). Moreover, the HS pollen reduced the number of seeds produced in all the cultivars. Using the HX pollen, HJ and XL produced more seeds than the cultivars pollinated using pollen from other cultivars. Therefore, pollen source affected the number of seeds produced by the $C$. oleifera cultivars.

The hundred-grain weight of self-pollinated plants was low; in cross-pollinated plants, however, it depended on the cultivar combination (Table 3 ). HX pollen effectively increased the hundred-grain weights of $\mathrm{HS}, \mathrm{HJ}$ and XL by $30.47 \%, 49.10 \%$, and $56.40 \%$, respectively. The hundred-grain weights were generally lower when XL was used as the pollen donor in cross-pollination combinations.

Pollen source affected the fresh and dry seed rates differently (Fig. 7A and B). The fresh seed rates of HS pollinated by HJ, HX, and XL were significantly higher than those of fruits of the self-pollinated and naturally pollinated plants, but the differences among the three pollen donors were not significant. Pollen from HX and XL increased the fresh seed rates of the cross-pollinated plants relative to those of naturally pollinated plants. However, the dry seed rates of selfpollinated HX and XL were significantly higher than those of naturally and crosspollinated plants.

The kernel rate of HS pollinated by XL was significantly higher than that of naturally pollinated plants, whereas it was significantly lower when pollinated with HX (Fig. 7C). In addition, HS pollen effectively increased the kernel rate of XL. Unexpectedly, selfpollinated $\mathrm{HJ}$ and $\mathrm{HX}$ plants had higher kernel rates than the corresponding cross-pollinated plants, even though self-pollination usually leads to seed dysplasia, resulting in a lower kernel yield.

Pollen source had both positive and negative effects on kernel oil contents (Fig. 7D). Compared with naturally pollinated plants, the kernel oil rates of HS and XL pollinated with HX were significantly lower, whereas $\mathrm{HS}$ pollen caused the kernel oil rate of $\mathrm{HJ}$ to be higher than that of naturally pollinated plants. However, the oil rate in crosspollinated HX plants was unaffected by pollen source.

Effects of pollen source on fatty acid contents. The palmitic, stearic, linoleic, and linolenic acid contents of the seeds varied with the pollen source. The variation in oleic acid content was not significant (Table 4). The palmitic acid contents of HS and HJ were not significantly affected by pollen source; palmitic acid content was slightly lower in HX and XL, but only when HS was used as the pollen donor. HJ pollen increased linoleic acid content in all cross-pollinated plants relative to naturally pollinated plants. Compared with naturally pollinated plants, the linoleic acid content was significantly higher in cross-pollinated HS, by $40.90 \%, 30.09 \%$, and $36.76 \%$, when 
pollinated by HJ, HX, and XL, respectively. The linolenic acid content was significantly higher in XL and HS combinations. How- ever, oleic acid content was not significantly affected by pollen source, in any of the cultivars. These results show that pollen
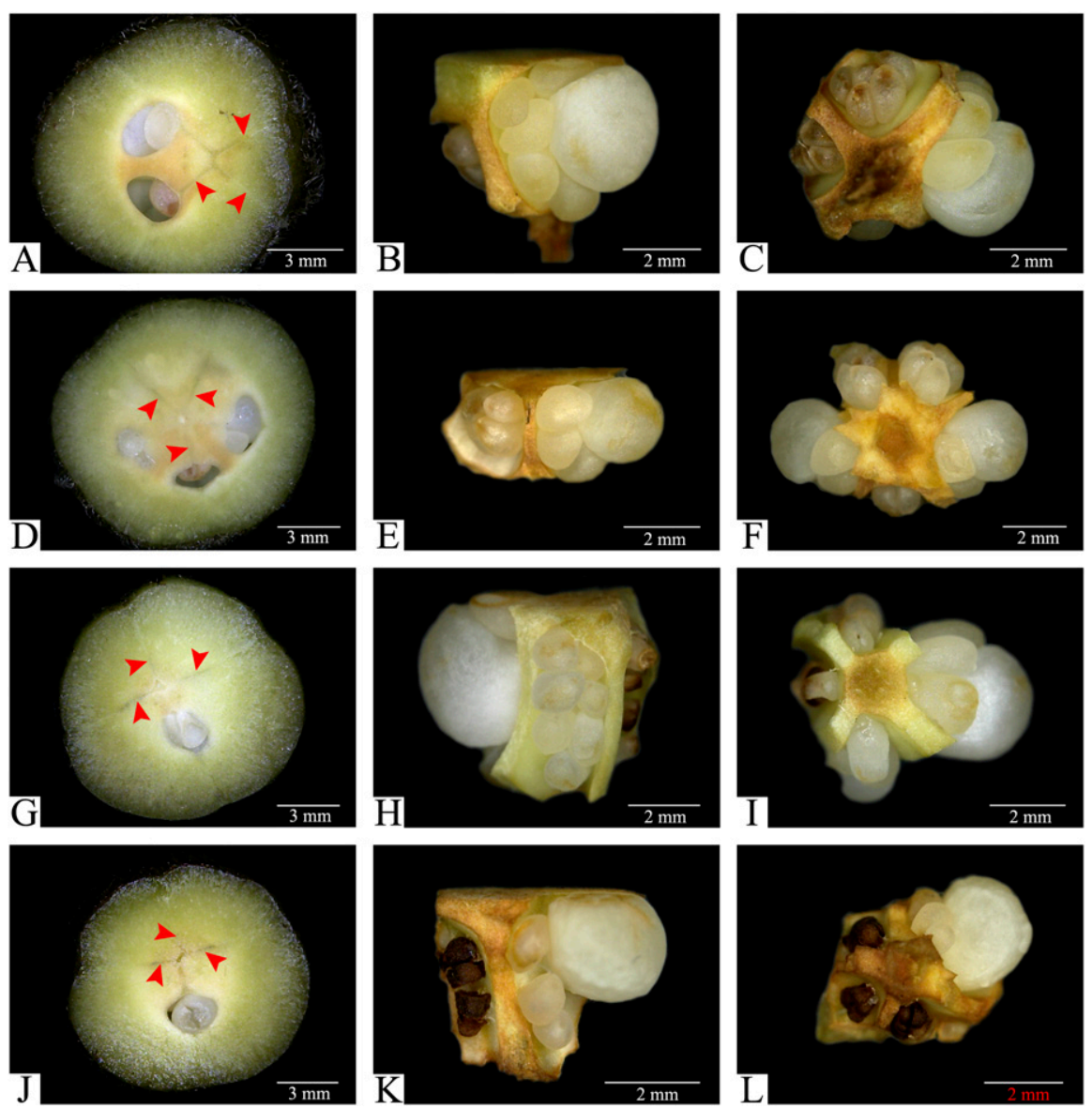

Fig. 6. The development of young fruits and ovules at $180 \mathrm{~d}$ after self-pollination. The cross section, equatorial, and polar view of young fruits and ovules of self-pollinated HS (A-C), HX (D-F), HJ (GI), and XL (J-L) are shown. source had variable effects on the fatty acid content of $C$. oleifera.

$P C A$ and evaluation of the effect of different pollen types. The fruit set, fruit weight, vertical and horizontal diameter, peel thickness, seed number, hundred-seed weight, and linoleic acid contents were the dominant contributors to $\mathrm{PC} 1$, with a variance contribution of $39.74 \%$. The variance contribution of the PC2 was $18.47 \%$; this PC mainly reflects the contribution of kernel rate and linolenic acid. PC3 denotes fresh seed rate, kernel oil rate, palmitic and stearic acid content, with a variance contribution of $12.79 \%$. Dry seed rate was the largest contributor to PC4, which contributed $8.15 \%$ of the variance. The variance contribution of PC5 was $6.56 \%$, with oleic acid as the dominant contributor. The cumulative variance contribution of the first five components was $85.71 \%$. This indicates that these five principal components effectively summarize the factors affecting C. oleifera yield and quality (Supplemental Table 2).

To determine the optimal pollinating male parent among the four $C$. oleifera cultivars, PCA was used to evaluate 20 pollination combinations. The comprehensive principal component score model was $\mathrm{S}=0.19 \mathrm{ZX}_{1}+$ $0.17 Z X_{2}+0.19 Z X_{3}+0.21 Z X_{4}-0.13 Z X_{5}+$ $0.20 \mathrm{ZX}_{6}+0.19 \mathrm{ZX} \mathrm{X}_{7}+0.18 \mathrm{ZX}_{8}+0.11 \mathrm{ZX}_{9}+$ $0.02 \mathrm{ZX}_{10}-0.06 \mathrm{ZX}_{11}+0.06 \mathrm{ZX} \mathrm{X}_{12}-0.01 \mathrm{ZX}_{13}+$ $0.01 \mathrm{ZX}_{14}+0.04 \mathrm{ZX}_{15}-0.06 \mathrm{ZX}_{16}$. Pollination combinations with a higher score are more suitable pollinators. All self-pollinated plants exhibited lower comprehensive scores than cross-pollinated and naturally pollinated plants (Table 5). Among the crosspollination combinations, HS $\times \mathrm{HX}$ had the highest comprehensive score, followed by $\mathrm{HS} \times \mathrm{HJ}$ and $\mathrm{HS} \times \mathrm{XL}$. Pollen from HX exhibited a higher comprehensive score in $\mathrm{HJ}$ and XL cross-pollinated plants, indicating

Table 1. The effects of pollen source on the fruit traits of $C$. oleifera.

\begin{tabular}{|c|c|c|c|c|c|}
\hline Female & Male & Fruit wt (g) & Vertical diam $(\mathrm{mm})$ & Horizontal diam (mm) & Peel thickness $(\mathrm{mm})$ \\
\hline \multirow[t]{3}{*}{ HS } & HS & $27.24 \pm 2.77 \mathrm{~d}$ & $24.63 \pm 1.26 \mathrm{c}$ & $26.61 \pm 1.01 \mathrm{c}$ & $5.23 \pm 0.32 \mathrm{c}$ \\
\hline & HX & $88.46 \pm 2.49 \mathrm{a}$ & $44.10 \pm 3.81 \mathrm{a}$ & $56.97 \pm 3.51 \mathrm{a}$ & $7.50 \pm 0.50 \mathrm{a}$ \\
\hline & $\mathrm{XL}$ & $79.21 \pm 2.57 b$ & $50.16 \pm 5.74 \mathrm{a}$ & $46.07 \pm 4.65 b$ & $6.86 \pm 0.67 \mathrm{ab}$ \\
\hline LSD $_{0.05}$ & & 4.84 & 6.66 & 6.82 & 0.92 \\
\hline \multirow[t]{3}{*}{ HJ } & HS & $29.88 \pm 2.15 b$ & $40.09 \pm 3.53 \mathrm{ab}$ & $38.30 \pm 2.84 \mathrm{ab}$ & $5.95 \pm 0.65 \mathrm{ab}$ \\
\hline & HJ & $23.13 \pm 2.19 \mathrm{c}$ & $35.58 \pm 2.36 \mathrm{~b}$ & $34.24 \pm 3.54 b$ & $5.78 \pm 0.71 \mathrm{~b}$ \\
\hline & CK & $27.92 \pm 2.02 b$ & $41.20 \pm 3.61 \mathrm{ab}$ & $36.87 \pm 4.72 \mathrm{ab}$ & $6.37 \pm 0.54 \mathrm{ab}$ \\
\hline $\mathrm{LSD}_{0.05}$ & & 4.38 & 5.59 & 7.17 & 1.08 \\
\hline \multirow[t]{5}{*}{ HX } & HS & $33.49 \pm 2.11 \mathrm{~b}$ & $33.56 \pm 2.24 \mathrm{ab}$ & $40.32 \pm 1.91 \mathrm{a}$ & $4.78 \pm 0.22 b$ \\
\hline & HJ & $40.15 \pm 2.90 \mathrm{a}$ & $35.94 \pm 3.74 \mathrm{a}$ & $44.53 \pm 4.12 \mathrm{a}$ & $5.93 \pm 0.88 \mathrm{a}$ \\
\hline & HX & $15.33 \pm 2.04 \mathrm{c}$ & $26.31 \pm 4.28 \mathrm{~b}$ & $30.01 \pm 6.93 \mathrm{~b}$ & $3.54 \pm 0.23 \mathrm{c}$ \\
\hline & XL & $38.60 \pm 2.73 \mathrm{a}$ & $35.25 \pm 3.33 \mathrm{a}$ & $43.74 \pm 4.13 \mathrm{a}$ & $4.94 \pm 0.51 \mathrm{ab}$ \\
\hline & CK & $30.39 \pm 0.72 b$ & $35.01 \pm 5.79 \mathrm{a}$ & $38.18 \pm 3.51 \mathrm{a}$ & $4.52 \pm 0.86 \mathrm{bc}$ \\
\hline XL & $\mathrm{CK}$ & $26.13 \pm 2.38 \mathrm{c}$ & $31.85 \pm 2.96 \mathrm{~b}$ & $37.34 \pm 2.60 \mathrm{~b}$ & $4.58 \pm 0.44 \mathrm{bc}$ \\
\hline $\mathrm{LSD}_{0.05}$ & & 3.63 & 4.94 & 5.40 & 1.11 \\
\hline
\end{tabular}

Data represent the mean \pm SD of three replications. Mean values followed by different lowercase letters in each column indicate significant differences at $P<0.05$ in a least significant difference (LSD) test. 


\begin{tabular}{lcrrr}
\hline & & \multicolumn{3}{c}{ Female } \\
\cline { 2 - 5 } Male & HS & HJ & HX & XL \\
\hline HS & $2.30 \pm 0.48 \mathrm{~b}$ & $9.70 \pm 1.05 \mathrm{c}$ & $8.90 \pm 0.99 \mathrm{~b}$ & \\
HJ & $19.50 \pm 1.08 \mathrm{a}$ & $2.30 \pm 0.48 \mathrm{~d}$ & $14.80 \pm 1.03 \mathrm{a}$ & $11.50 \pm 0.97 \mathrm{~b}$ \\
HX & $20.20 \pm 1.03 \mathrm{a}$ & $14.90 \pm 0.74 \mathrm{a}$ & $2.70 \pm 0.67 \mathrm{c}$ & $11.90 \pm 0.74 \mathrm{a}$ \\
XL & $19.50 \pm 1.17 \mathrm{a}$ & $11.10 \pm 1.10 \mathrm{~b}$ & $15.50 \pm 0.71 \mathrm{a}$ & $2.10 \pm 0.57 \mathrm{c}$ \\
CK & $19.40 \pm 1.34 \mathrm{a}$ & $10.40 \pm 0.97 \mathrm{bc}$ & $9.10 \pm 0.73 \mathrm{~b}$ & $9.80 \pm 0.92 \mathrm{~b}$ \\
LSD $_{0.05}$ & 0.96 & 0.81 & 0.76 & 0.71 \\
\hline
\end{tabular}

Data represent the mean \pm SD of three replications. Mean values followed by different lowercase letters in each column indicate significant differences at $P<0.05$ in a least significant difference (LSD) test.

Table 3. The effects of pollen source on hundred-grain weight of C. oleifera $(\mathrm{g})$.

\begin{tabular}{lcccc}
\hline & & & Female & \\
\cline { 2 - 5 } Male & HS & HJ & HX & XL \\
HS & $153.23 \pm 9.59 \mathrm{~d}$ & $213.89 \pm 17.45 \mathrm{~b}$ & $206.68 \pm 22.67 \mathrm{~b}$ & $207.84 \pm 18.07 \mathrm{~b}$ \\
$\mathrm{HJ}$ & $275.98 \pm 21.52 \mathrm{a}$ & $135.17 \pm 7.15 \mathrm{~d}$ & $135.69 \pm 12.87 \mathrm{a}$ & $157.36 \pm 8.97 \mathrm{c}$ \\
$\mathrm{HX}$ & $248.68 \pm 12.34 \mathrm{~b}$ & $257.67 \pm 20.99 \mathrm{a}$ & $164.01 \pm 10.21 \mathrm{c}$ & $247.99 \pm 16.94 \mathrm{a}$ \\
XL & $231.08 \pm 14.10 \mathrm{~b}$ & $185.12 \pm 16.17 \mathrm{c}$ & $172.17 \pm 10.19 \mathrm{c}$ & $125.07 \pm 8.06 \mathrm{~d}$ \\
CK & $190.60 \pm 6.53 \mathrm{c}$ & $172.82 \pm 11.03 \mathrm{c}$ & 25.24 & $158.56 \pm 11.64 \mathrm{c}$ \\
LSD $_{0.05}$ & 25.06 & 27.94 & 24.33 \\
\hline
\end{tabular}

Data represent the mean \pm SD of three replications. Mean values followed by different lowercase letters in each column indicate significant differences at $P<0.05$ in least significant difference (LSD) test.
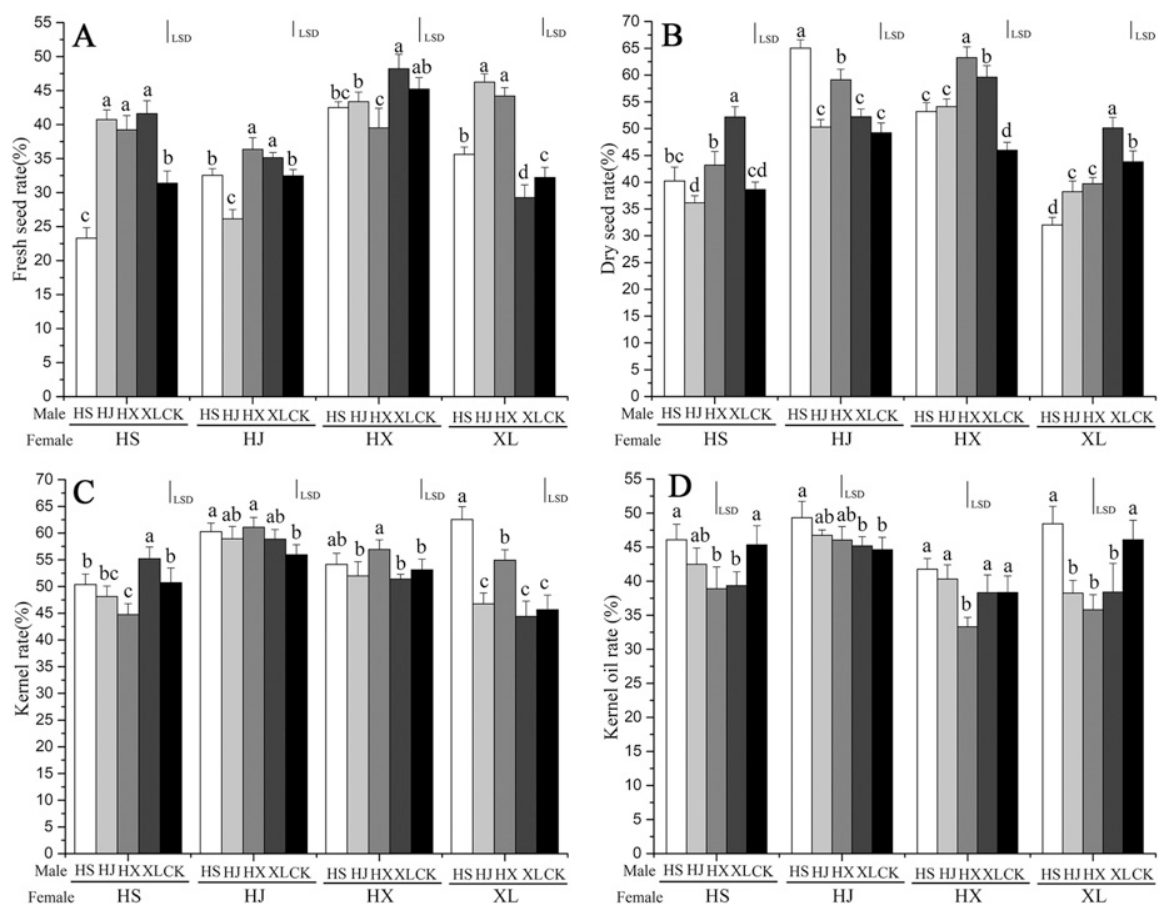

Fig. 7. Comparison of the fresh seed rate (A), dry seed rate (B), kernel rate (C), and kernel oil rate (D) of different pollination combinations. The data are the mean \pm SD of three biological replicates, and different lowercase letters indicate significant differences at 5\% probability level in a least significant difference (LSD) test.

that HX had a positive influence on $C$. oleifera yield and quality when it was used as the pollen donor.

\section{Discussion}

In flowering plants, pollination is the key event in the development of the fruit set, influencing fruit quantity and quality (Jahromi et al., 2019; Selak et al., 2014). The development of self-incompatibility systems in plants is a long-term evolutionary process that ensures genetic diversity (Perez et al., 2016; Wang et al., 2017). In this study, there was no significant difference in pollen germination and pollen tube growth in the style between the cross-pollination and selfpollination treatments. The cross-pollination tube was able to penetrate the ovule, but the self-pollination tube stagnated at the base of the style and finally failed in fertilization. Although self-pollination was able to produce a fruit set, the fruit set was much lower than in cross-pollinated plants. Furthermore, the aborted ovules and seeds that occurred in the self-pollinated fruits are examples of late- acting self-incompatibility, which is consistent with previous studies (Gao et al., 2015b; Gibbs, 2014; Liao et al., 2014b; Liu et al., 2014).

There were significant differences in fruit set and fruit traits of the four cultivars when pollen from different cultivars was used for cross-pollination. The four $C$. oleifera cultivars pollinated by different pollen sources showed significant differences in fruit traits such as fruit longitudinal diameter, fruit transverse diameter, and peel thickness. These findings are like those of previous studies that report xenia in cherimoya (Kahn et al., 1994), pistachio (Acar and Eti, 2011), and date palm (Rezazadeh et al., 2013). Xenia has also been observed in the development of tomato and sweet cherry fruits (Piotto et al., 2013; Radunic et al., 2017).

Pollen source influenced the seed number, hundred-grain weight, fresh seed rate, dry seed rate, kernel rate, and kernel oil rate of the four $C$. oleifera cultivars to different extents. HJ and XL exhibited a certain degree of xenia regarding these six traits; in contrast, HS and HX exhibited no direct xenia regarding seed number and kernel rate. Xenia was positive for the dry seed rate of HS, HJ, and HX, but it was negative for XL. Xenia has also been reported in other plants regarding seed traits. For instance, Herbert et al. (2019b) found that pollen source had a positive impact on fruit growth, nut size, and kernel size in macadamia. According to Fattahi et al. (2014), hazelnut nut weight was significantly affected by pollen source, whereas self-pollination reduced its nut and kernel trait values and increased the proportion of blank nuts. Xenia typically positively influences the yield and quality of economic crops, but it sometimes has a negative impact. Ismail et al. (2016) found that xenia negatively affected coconut nut yield. Therefore, studies on xenia in $C$. oleifera regarding fruit and seed characteristics are necessary to improve its oil yield. 
Table 4. The effects of pollen source on fatty acid contents of C. oleifera $(\%)$.

\begin{tabular}{|c|c|c|c|c|c|c|}
\hline Female & Male & Palmitate acid & Stearic acid & Oleic acid & Linoleic acid & Linolenic acid \\
\hline \multirow[t]{3}{*}{$\overline{\mathrm{HS}}$} & HS & $7.14 \pm 0.070$ & $2.36 \pm 0.050$ & $82.43 \pm 0.04$ & $7.35 \pm 0.003 \mathrm{a}$ & $0.72 \pm 0.002 \mathrm{~b}$ \\
\hline & $\mathrm{HX}$ & $7.13 \pm 0.050$ & $2.58 \pm 0.030$ & $82.30 \pm 0.04$ & $7.22 \pm 0.003 \mathrm{a}$ & $0.78 \pm 0.001 \mathrm{~b}$ \\
\hline & XL & $7.75 \pm 0.050$ & $2.45 \pm 0.030$ & $81.23 \pm 0.03$ & $7.59 \pm 0.005 \mathrm{a}$ & $0.98 \pm 0.001 \mathrm{a}$ \\
\hline $\mathrm{LSD}_{0.05}$ & & NS & NS & NS & 0.93 & 0.14 \\
\hline \multirow[t]{3}{*}{$\mathrm{HJ}$} & HS & $7.62 \pm 0.004$ & $2.73 \pm 0.003 \mathrm{ab}$ & $83.54 \pm 0.01$ & $6.11 \pm 0.006 \mathrm{a}$ & - \\
\hline & HJ & $8.14 \pm 0.009$ & $2.39 \pm 0.005 b$ & $82.89 \pm 0.02$ & $6.04 \pm 0.006 \mathrm{a}$ & $0.54 \pm 0.0005 b$ \\
\hline & CK & $6.90 \pm 0.009$ & $3.30 \pm 0.003 \mathrm{a}$ & $84.22 \pm 0.02$ & $4.89 \pm 0.004 b$ & $0.69 \pm 0.001 \mathrm{a}$ \\
\hline $\mathrm{LSD}_{0.05}$ & & NS & 0.84 & NS & 0.88 & 0.11 \\
\hline \multirow[t]{5}{*}{$\mathrm{HX}$} & HS & $6.61 \pm 0.080 \mathrm{~b}$ & $2.70 \pm 0.004 \mathrm{ab}$ & $84.32 \pm 0.03$ & $5.72 \pm 0.004 b$ & $0.65 \pm 0.001$ \\
\hline & HJ & $7.07 \pm 0.060 \mathrm{ab}$ & $2.45 \pm 0.005 \mathrm{~b}$ & $82.99 \pm 0.03$ & $6.78 \pm 0.006 \mathrm{a}$ & $0.71 \pm 0.001$ \\
\hline & HX & $7.31 \pm 0.070 \mathrm{ab}$ & $2.79 \pm 0.004 \mathrm{ab}$ & $83.77 \pm 0.03$ & $5.51 \pm 0.004 b$ & $0.62 \pm 0.002$ \\
\hline & XL & $7.04 \pm 0.070 \mathrm{ab}$ & $3.35 \pm 0.004 \mathrm{a}$ & $83.85 \pm 0.03$ & $5.13 \pm 0.003 b$ & $0.63 \pm 0.002$ \\
\hline & $\mathrm{CK}$ & $7.77 \pm 0.060 \mathrm{a}$ & $1.97 \pm 0.004 \mathrm{~b}$ & $82.82 \pm 0.03$ & $6.66 \pm 0.005 \mathrm{a}$ & $0.78 \pm 0.001$ \\
\hline $\mathrm{XL}$ & $\mathrm{CK}$ & $7.73 \pm 0.003 \mathrm{a}$ & $1.93 \pm 0.004 \mathrm{~b}$ & $84.23 \pm 0.04$ & $5.54 \pm 0.007 \mathrm{bc}$ & $0.57 \pm 0.005 b$ \\
\hline $\mathrm{LSD}_{0.05}$ & & 0.45 & 0.73 & NS & 1.19 & 0.16 \\
\hline
\end{tabular}

Data represent the mean \pm SD of three replications. Mean values followed by different lowercase letters in each column indicate significant differences at $P<0.05$ in least significant difference (LSD) test. NS $=$ not significant.

Table 5. Comprehensive score and ranking of different pollination combinations.

\begin{tabular}{lccc}
\hline Female & Male & Comprehensive score & Ranking \\
\hline HS & HS & -2.08 & 19 \\
& HJ & 1.79 & 2 \\
& HX & 2.01 & 1 \\
& XL & 1.76 & 3 \\
HJ & CK & -0.25 & 12 \\
& HS & 0.26 & 8 \\
& HJ & -1.48 & 17 \\
& HX & 1.37 & 4 \\
& XL & 0.22 & 9 \\
HX & CK & -0.31 & 13 \\
& HS & 0.18 & 10 \\
& HJ & 0.89 & 5 \\
& HX & -1.51 & 18 \\
& XL & 0.67 & 7 \\
XL & CK & -0.45 & 15 \\
& HS & -0.44 & 14 \\
& HJ & -0.07 & 11 \\
& HX & 0.75 & 6 \\
& XL & -2.28 & 20 \\
& CK & -1.03 & 16 \\
\hline
\end{tabular}

The comprehensive score and ranking reflect the pros and cons of each pollination combination (the higher the score, the better the effect).

Xenia significantly affects oleic and linoleic acid contents in almond (Kodad et al., 2009), and pollen source possibly affects fatty acid content and composition in tree peony oil (Xie et al., 2019). In the present study, compared with the fruits from naturally pollinated plants, fruits originating from cross-pollination of $\mathrm{HJ}$ with $\mathrm{HS}$ as the pollen donor had higher linoleic acid content; whereas this content was significantly lower in HX when HS and XL were used as pollen donors. Compared with naturally pollinated HJ plants, the linolenic acid content in the cross- and self-pollinated HJ plants was significantly lower. However, in the pollination combinations $\mathrm{XL} \times \mathrm{HS}, \mathrm{XL} \times$ $\mathrm{HJ}$, and $\mathrm{HS} \times \mathrm{XL}$, the linolenic acid content was significantly higher than in under natural pollination. These results show that pollen source can affect linoleic and linolenic acid contents, thus affecting the quality of tea oil.

\section{Conclusions}

This study reports pollination compatibility and xenia regarding fruit and seed traits in four $C$. oleifera cultivars. In the crosspollination treatment, the pollen tubes were able to penetrate the ovules, whereas in the self-pollination treatment, they remained at the base of the style. The stagnated growing pollen tubes, severe ovule abortion, and low fruit set of the self-pollination combination reflect the self-incompatibility of $C$. oleifera. Pollen source significantly affected the oil yield and quality indices, including single fruit weight, seed number, hundred-grain weight, fresh seed rate, dry seed rate, kernel rate, kernel oil rate, and the fatty acid content, to varying degrees, implying xenia in $C$. oleifera. HX was the most effective pollination cultivar, and HS $\times$ HX was the optimal cross-pollination combination, resulting in the best oil yield and quality. This research indicates that the scientific selection of pollination cultivars has great potential to improve the yield and oil quality of $C$. oleifera and may help growers to enhance profitability and sustainability.

\section{Literature Cited}

Acar, I. and S. Eti. 2011. Nut quality of 'Kirmizi', 'Siirt' and 'Ohadi' pistachio cultivars as affected by different pollinators. Acta Hort. 912:81-86.

Asatryan, A. and N. Tel-Zur. 2013. Pollen tube growth and self-incompatibility in three Ziziphus species (Rhamnaceae). Flora 208:390399.
Chen, X., S. Hao, L. Wang, W. Fang, Y. Wang, and X. Li. 2012. Late-acting self-incompatibility in tea plant (Camellia sinensis). Biologia 67:347351.

Cheng, Y.T., S.L. Wu, C.Y. Ho, S.M. Huang, C.L. Cheng, and G.C. Yen. 2014. Beneficial effects of camellia oil (Camellia oleifera Abel.) on ketoprofen-induced gastrointestinal mucosal damage through upregulation of HO-1 and VEGF. J. Agr. Food Chem. 62:642-650.

Denny, J.O. 1992. Xenia includes metaxenia. HortScience 27:722-728.

Faehnrich, B., C. Kraxner, S. Kummer, and C. Franz. 2015. Pollen tube growth and selfincompatibility in Matricaria recutita. Euphytica 206:357-363.

Fattahi, R., M. Mohammadzedeh, and A. KhadiviKhub. 2014. Influence of different pollen sources on nut and kernel characteristics of hazelnut. Scientia Hort. 173:15-19.

Gao, C., D.Y. Yuan, Y. Yang, B.F. Wang, D.M. Liu, F. Zou, and X.F. Tan. 2015a. Anatomical characteristics of self-incompatibility in $\mathrm{Ca}$ mellia oleifera. Sci. Sil. Sin. 51:60-68.

Gao, C., D.Y. Yuan, Y. Yang, B.F. Wang, D.M. Liu, and F. Zou. 2015b. Pollen tube growth and double fertilization in Camellia oleifera. J. Amer. Soc. Hort. Sci. 140:12-18.

Gibbs, P.E. 2014. Late-acting self-incompatibilityThe pariah breeding system in flowering plants. New Phytol. 203:717-734.

Herbert, S.W., D.A. Walton, and H.M. Wallace. 2019a. Pollen-parent affects fruit, nut and kernel development of Macadamia. Scientia Hort. 244:406-412.

Herbert, S.W., D.A. Walton, and H.M. Wallace. $2019 \mathrm{~b}$. The influence of pollen-parent and carbohydrate availability on macadamia yield and nut size. Scientia Hort. 251:241-246.

Higashiyama, T. 2010. Peptide signaling in pollenpistil interactions. Plant Cell Physiol. 51:177189.

Ismail, M., L.S. Halimah, N. Hengky, and S. Sudarsono. 2016. Xenia negatively affecting kopyor nut yield in Kalianda Tall kopyor and Pati Dwarf kopyor coconuts. Emir. J. Food Agr. 28:644-652. 
Jahromi, H.A., A. Zarei, and A. Mohammadkhani. 2019. Analysis the effects of pollen grain sources on the fruits set and their characteristics of 'Clementine' mandarin using microscopic and molecular approaches. Scientia Hort. 249:347-354.

Jia, H.J., F.J. He, C.Z. Xiong, F.R. Zhu, and G. Okamoto. 2008. Influences of cross pollination on pollen tube growth and fruit set in Zuili plums (Prunus salicina). J. Integr. Plant Biol. 50:203-209.

Kahn, T.L., C.J. Adams, and M.L. Arpaia. 1994. Paternal and maternal effects on fruit and seed characteristics in cherimoya (Annona cherimola Mill.). Scientia Hort. 59:11-25.

Kodad, O., G. Estopañán, T. Juan, and R. Socias i Company. 2009. Xenia effects on oil content and fatty acid and tocopherol concentrations in autogamous almond cultivars. J. Agr. Food Chem. 57:10809-10813.

Liao, T., D.Y. Yuan, C. Gao, F. Zou, J. Tang, and X.F. Tan. 2014a. Pollination, fertilization and early embryonic development of Camellia oleifera. Sci. Sil. Sin. 50:50-55.

Liao, T., D.Y. Yuan, F. Zou, C. Gao, Y. Yang, L. Zhang, and X.F. Tan. 2014b. Self-sterility in Camellia oleifera may be due to the prezygotic late-acting self-incompatibility. PLoS One 9, doi: 10.1371/journal.pone.0099639.

Liu, J., H. Zhang, Y. Cheng, J. Wang, Y. Zhao, and W. Geng. 2014. Comparison of ultrastructure, pollen tube growth pattern and starch content in developing and abortive ovaries during the progarnic phase in hazel. Front. Plant Sci. 5, doi: $10.3389 /$ fpls.2014.00528.

Maryam, M.J. Jaskani, S. Ahmad, and F.S. Awan. 2015. Metaxenial effects on morphological attributes in date palm cvs. Hillawi and Khadrawy. Pak. J. Agr. Sci. 52:387-393.

Perez, V., M. Herrero, and J.I. Hormaza. 2016. Selffertility and preferential cross-fertilization in mango (Mangifera indica). Scientia Hort. 213:373-378.

Piotto, F.A., K.D. Batagin-Piotto, M. de Almeida, and G.C. Xavier Oliveira. 2013. Interspecific xenia and metaxenia in seeds and fruits of tomato. Sci. Agr. 70:102-107.

Pozzi, F.I., G.R. Pratta, C.A. Acuna, and S.A. Felitti. 2019. Xenia in bahiagrass: Gene ex- pression at initial seed formation. Seed Sci. Res. 29:29-37.

Radunic, M., A. Jazbec, S. Ercisli, Z. Cmelik, and S.G. Ban. 2017. Pollen-pistil interaction influence on the fruit set of sweet cherry. Scientia Hort. 224:358-366.

Rezazadeh, R., H. Hassanzadeh, Y. Hosseini, Y. Karami, and R.R. Williams. 2013. Influence of pollen source on fruit production of date palm (Phoenix dactylifera L.) cv. Barhi in humid coastal regions of southern Iran. Scientia Hort. 160:182-188.

Sabir, A. 2015. Xenia and metaxenia in grapes: Differences in berry and seed characteristics of maternal grape cv. 'Narince' (Vitis vinifera L.) as influenced by different pollen sources. Plant Biol. 17(2):567-573.

Sanchez-Perez, R., G. Arrazola, M. Luisa Martin, N. Grane, and F. Dicenta. 2012. Influence of the pollinizer in the amygdalin content of almonds. Scientia Hort. 139:62-65.

Seavey, S.R. and K.S. Bawa. 1986. Late-acting self-incompatibility in angiosperms. Bot. Rev. 52(2):195-219.

Selak, G.V., J. Cuevas, S.G. Ban, and S. Perica. 2014. Pollen tube performance in assessment of compatibility in olive (Olea europaea L.) cultivars. Scientia Hort. 165:36-43.

Takayama, S. and A. Isogai. 2005. Selfincompatibility in plants. Annu. Rev. Plant Biol. 56:467-489.

Tatari, M., H. Abdollahi, and A. Mousavi. 2018. Effect of pollination on dropping of flowers and fruits in new quince (Cydonia oblonga Mill.) cultivar and promising genotypes. Scientia Hort. 231:126-132.

Upadyayula, N., J. Wassom, and M.O. Bohn. 2006. Quantitative trait loci analysis of phenotypic traits and principal components of maize tassel inflorescence architecture. Theor. Appl. Genet. 112:592-606

Wang, G.M., C. Gu, X. Qiao, B.Y. Zhao, Y.Q. Ke, B.B. Guo, P.P. Hao, K.J. Qi, and S.L. Zhang. 2017. Characteristic of pollen tube that grew into self-style in pear cultivar and parent assignment for cross-pollination. Scientia Hort. 216:226-233.
Wei, W., H. Wu, X. Li, X. Wei, W. Lu, and X. Zheng. 2019. Diversity, daily activity patterns, and pollination effectiveness of the insects visiting Camellia osmantha, C. vietnamensis, and $C$. oleifera in South China. Insects 10, doi: 10.3390/insects 10040098 .

Wen, Y., S.C. Su, L.Y. Ma, S.Y. Yang, Y.W. Wang, and X.N. Wang. 2018. Effects of canopy microclimate on fruit yield and quality of Camellia oleifera. Scientia Hort. 235:132-141.

Xie, L., J. Hu, Q. Zhang, Q. Sun, Y. Zhang, and L. Niu. 2019. Influence of pollen sources on the expression of FA and TAG biosynthetic pathway genes in seeds of Paeonia rockii during the rapid oil accumulation. Scientia Hort. 243:477483.

Xie, L., L. Niu, Y. Zhang, M. Jin, D. Ji, and X. Zhang. 2017. Pollen sources influence the traits of seed and seed oil in Paeonia ostii 'Feng Dan'. HortScience 52:700-705.

Yan, Z.G., D. Xiao, Y.-L. Xu, J. Ma, F. Liu, L.-H. Bai, and X.-J. Ma. 2019. Effects of metaxenia on the carbohydrate and mogroside content and related enzyme activities in Siraitia grosvenorii fruit. Acta Physiol. Plant. 41, doi: 10.1007/s11738-019-2887-9.

You, L., S. Yu, H. Liu, C. Wang, Z. Zhou, L. Zhang, and D. Hu. 2019. Effects of biogas slurry fertilization on fruit economic traits and soil nutrients of Camellia oleifera Abel. PLoS One 14, doi: 10.1371/journal.pone.0208289.

Zhang, S., Y.G. Pan, L. Zheng, Y. Yang, X. Zheng, B. Ai, Z. Xu, and Z. Sheng. 2019. Application of steam explosion in oil extraction of camellia seed (Camellia oleifera Abel.) and evaluation of its physicochemical properties, fatty acid, and antioxidant activities. Food Sci. Nutr. 7:1004-1016.

Zhou, Q. and Y. Zheng. 2015. Comparative de novo transcriptome analysis of fertilized ovules in Xanthoceras sorbifolium uncovered a pool of genes expressed specifically or preferentially in the selfed ovule that are potentially involved in late-acting self-incompatibility. PLoS One 10, doi: 10.1371/journal.pone.0140507.

Zhuang, R.L. 2008. Tea-oil tree (Camellia oleifera Abel) of China. Chinese Forestry Publish House, Beijing. 


\begin{tabular}{|c|c|c|c|c|c|}
\hline \multirow[b]{2}{*}{ Female } & \multicolumn{4}{|c|}{ Male } & \multirow[b]{2}{*}{ Natural pollination } \\
\hline & HS & HJ & HX & $\mathrm{XL}$ & \\
\hline$\overline{\mathrm{HS}}$ & $\mathrm{HS} \times \mathrm{HS}$ & $\mathrm{HS} \times \mathrm{HJ}$ & $\mathrm{HS} \times \mathrm{HX}$ & $\mathrm{HS} \times \mathrm{XL}$ & HS CK \\
\hline HJ & $\mathrm{HJ} \times \mathrm{HS}$ & $\mathrm{HJ} \times \mathrm{HJ}$ & $\mathrm{HJ} \times \mathrm{HX}$ & $\mathrm{HJ} \times \mathrm{XL}$ & HJ CK \\
\hline HX & $\mathrm{HX} \times \mathrm{HS}$ & $\mathrm{HX} \times \mathrm{HJ}$ & $\mathrm{HX} \times \mathrm{HX}$ & $\mathrm{HX} \times \mathrm{XL}$ & HX CK \\
\hline $\mathrm{XL}$ & $\mathrm{XL} \times \mathrm{HS}$ & $\mathrm{XL} \times \mathrm{HJ}$ & $\mathrm{XL} \times \mathrm{HX}$ & $\mathrm{XL} \times \mathrm{XL}$ & XL CK \\
\hline
\end{tabular}

Supplemental Table 2. The composition matrix and explanation of the total variance.

\begin{tabular}{lccrrr}
\hline & \multicolumn{5}{c}{ Component } \\
\cline { 2 - 6 } Traits & \multicolumn{1}{c}{1} & \multicolumn{1}{c}{. } & \multicolumn{1}{c}{5} \\
\hline Fruit set (\%) & 0.8 & 0.32 & 0.23 & -0.11 & -0.16 \\
Fruit weight (g) & 0.92 & -0.06 & -0.02 & 0.01 & 0.12 \\
vertical diameter (mm) & 0.8 & 0.44 & -0.15 & 0.16 & -0.07 \\
horizontal diameter (mm) & 0.94 & 0.1 & 0.11 & -0.03 & 0.23 \\
Peel thickness (mm) & -0.76 & -0.35 & 0.38 & 0.11 & 0.02 \\
Seed number & 0.87 & 0.13 & 0.11 & -0.06 & 0.28 \\
Hundred-seed weight (g) & 0.84 & 0.33 & 0.02 & -0.08 & 0.01 \\
Fresh seed rate (\%) & 0.52 & -0.1 & 0.69 & 0.29 & -0.03 \\
Dry seed rate (\%) & -0.26 & 0.54 & 0.22 & 0.67 & 0.13 \\
Kernel rate (\%) & -0.12 & 0.69 & -0.15 & 0.13 & -0.54 \\
Oil rate of kernel (\%) & -0.11 & 0.49 & -0.71 & -0.4 & 0.06 \\
Palmitate acid (\%) & -0.03 & 0.36 & 0.60 & -0.57 & 0.06 \\
Stearic acid (\%) & 0.27 & -0.48 & -0.49 & 0.22 & 0.45 \\
Oleic acid (\%) & -0.58 & 0.54 & 0.16 & -0.13 & 0.54 \\
Linoleic acid (\%) & 0.69 & -0.46 & -0.28 & 0.15 & -0.2 \\
Linolenic acid (\%) & 0.25 & -0.73 & 0.23 & -0.35 & -0.18 \\
Eigenvalues & 6.36 & 2.96 & 2.05 & 1.31 & 1.05 \\
Variance & 39.74 & 18.47 & 12.79 & 8.15 & 6.56 \\
Accumulative variance & 39.74 & 58.21 & 71 & 79.15 & 85.71 \\
\hline
\end{tabular}

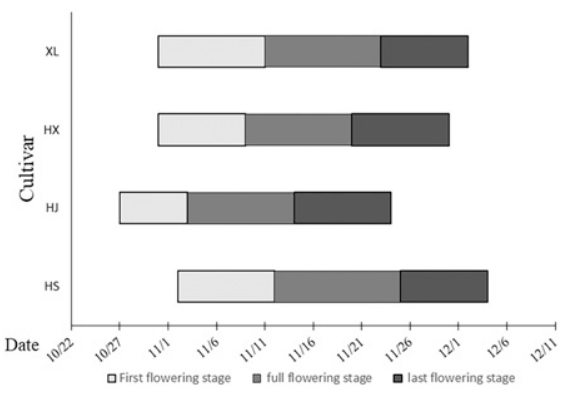

Supplemental Fig. 1. Flowering periods of four $C$. oleifera cultivars. The first flowering stage is $5 \%$ to $25 \%$ the length of the flowering phase of the whole tree, full flowering stage is $25 \%$ to $75 \%$ the length of the flowering phase of the whole tree, last flowering stage is more than $75 \%$ the length of the flowering phase of the whole tree.
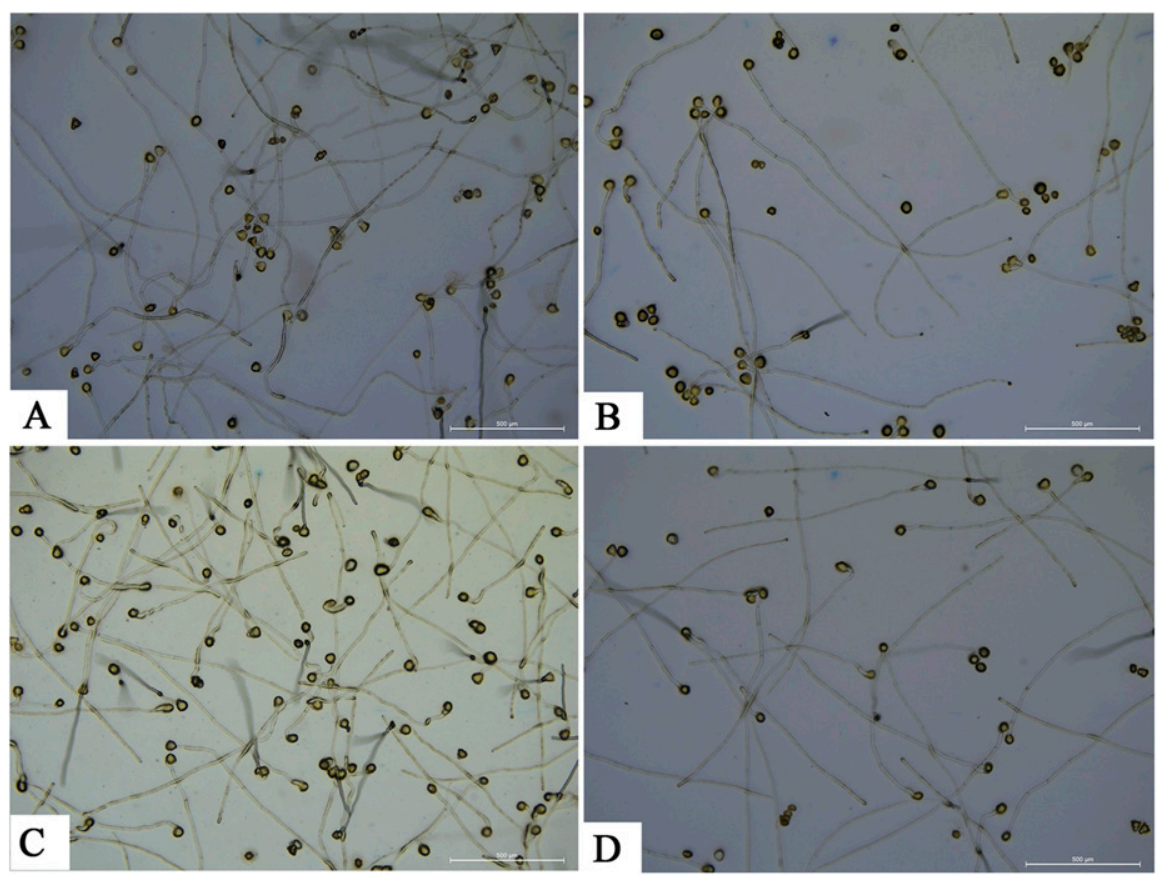

Supplemental Fig. 2. Pollen germination of Four C. oleifera cultivars on the culture medium. HS (A), HJ (B), HX (C), and XL (D) 


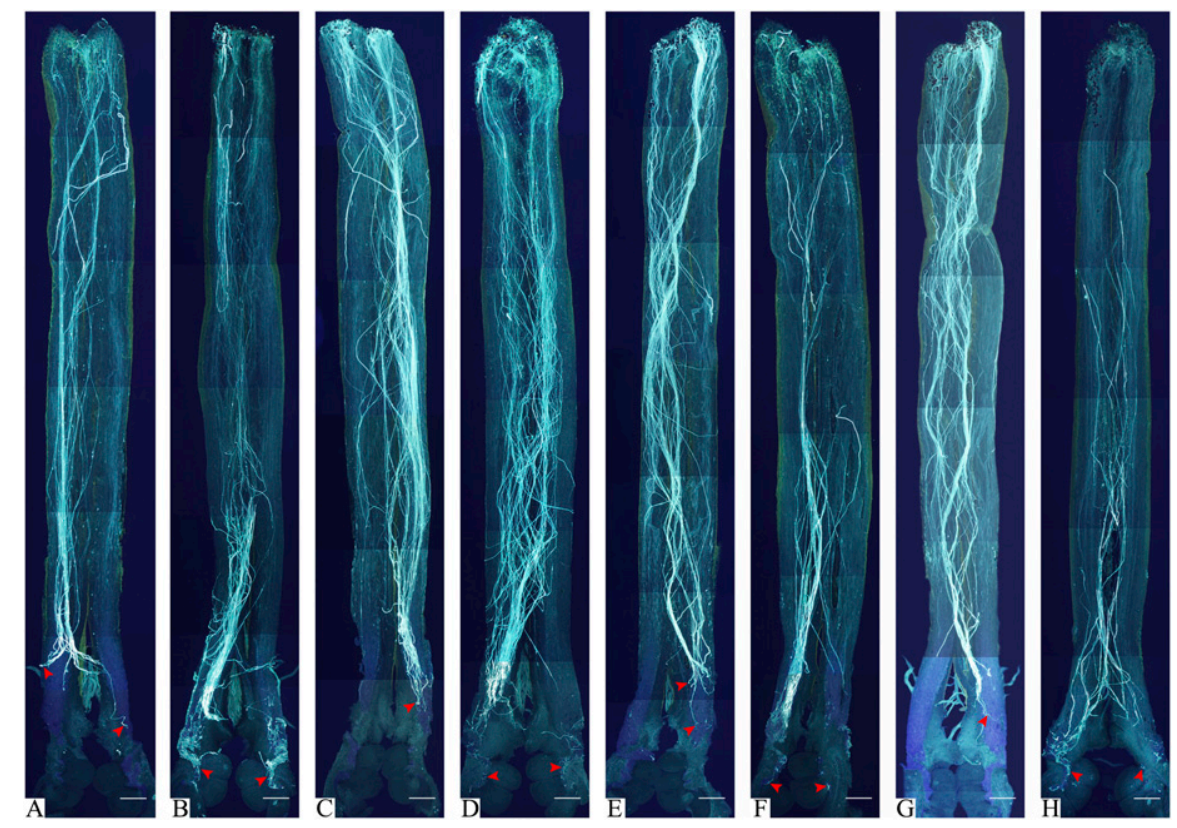

Supplemental Fig. 3. A complete view of pollen tube growth at $40 \mathrm{~h}$ after pollination in the styles and ovaries of $C$. oleifera. The pollen tube growth in self-pollination of HS (A), XL (B), HJ (C), and HX (D); the pollen tube growth in cross-pollination of $\mathrm{HS} \times \mathrm{XL}(\mathbf{E}), \mathrm{XL} \times \mathrm{HS}(\mathbf{F}), \mathrm{HJ} \times \mathrm{HX}(\mathbf{G})$, and $\mathrm{HX} \times$ HJ (H). Bars A-H: $800 \mu \mathrm{m}$.
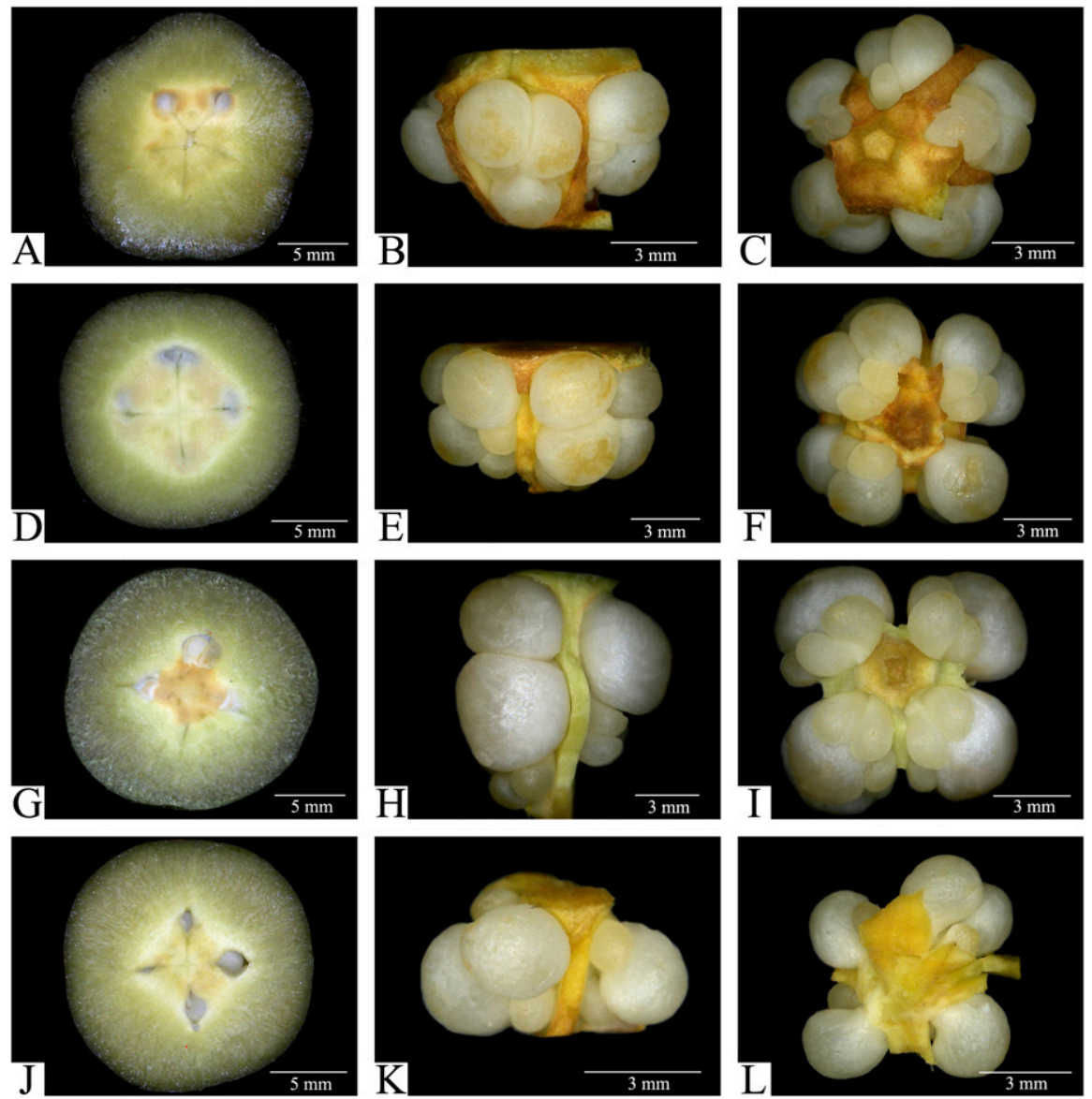

Supplemental Fig. 4. The development of young fruits and ovules at $180 \mathrm{~d}$ after cross-pollination. The cross section, equatorial, and polar view of young fruits and ovules in cross-pollination of $\mathrm{HS} \times \mathrm{XL}(\mathbf{A}-$ $\mathbf{C}), \mathrm{XL} \times \mathrm{HS}(\mathbf{D}-\mathbf{F}), \mathrm{HJ} \times \mathrm{HX}(\mathbf{G}-\mathbf{I})$, and $\mathrm{HX} \times \mathrm{HJ}(\mathbf{J}-\mathbf{L})$ are shown. 


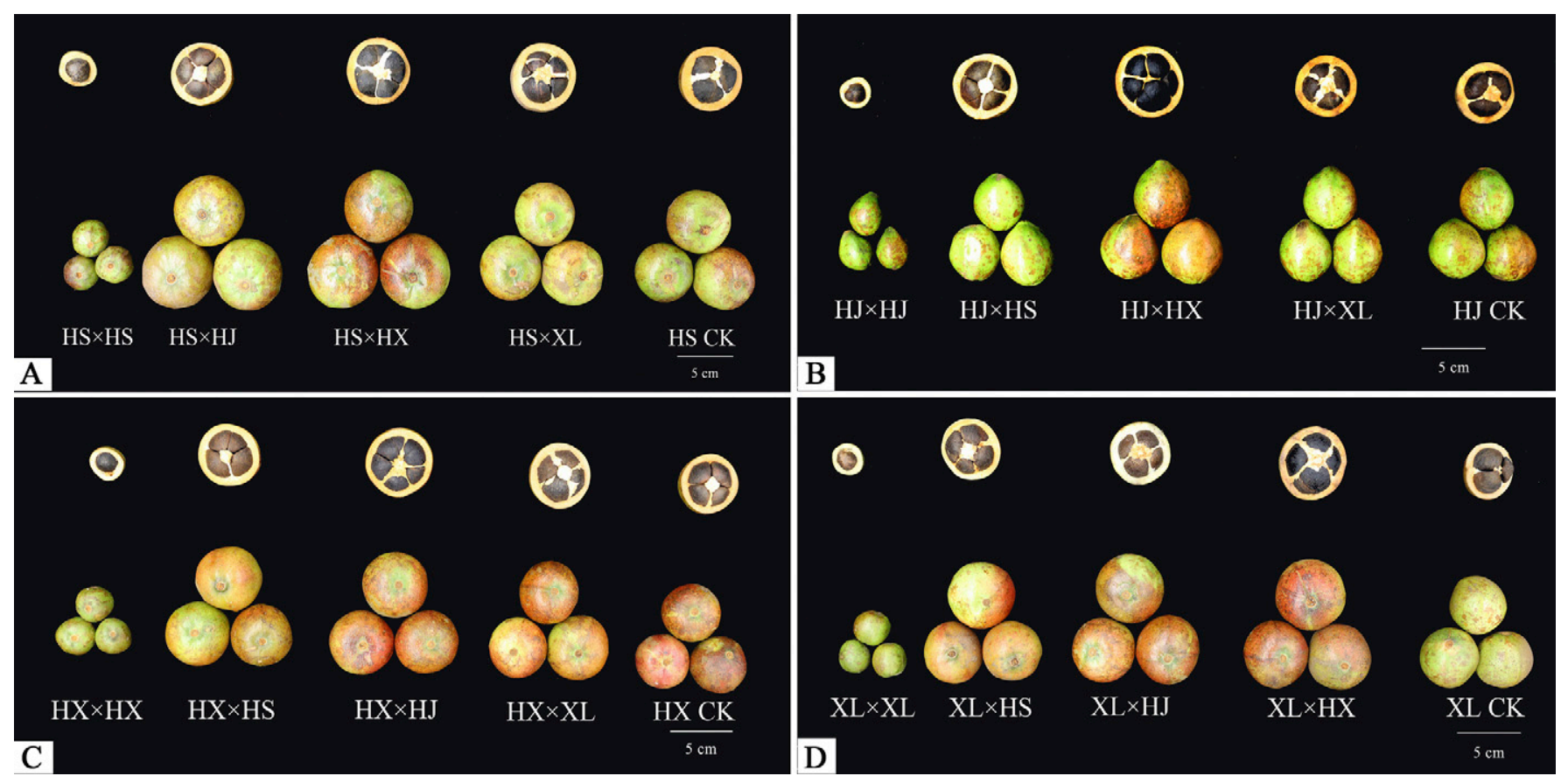

Supplemental Fig. 5. The effects of pollen source on fruit size and seed shell color of C. oleifera. HS pollinated by different pollen sources (A), HJ pollinated by different pollen sources (B), HX pollinated by different pollen sources (C), XL pollinated by different pollen sources (D). 